\title{
"Beet-ing" the Mountain: A Review of the Physiological and Performance Effects of Dietary Nitrate Supplementation at Simulated and Terrestrial Altitude
}

\author{
Oliver Michael Shannon ${ }^{1}$ (D) Kerry McGawley ${ }^{2} \cdot$ Linn Nybäck $^{2} \cdot$ Lauren Duckworth $^{1} \cdot$ \\ Matthew John Barlow ${ }^{1}$ David Woods ${ }^{1,3} \cdot$ Mario Siervo $^{4} \cdot$ John Paul O'Hara $^{1}$
}

Published online: 2 June 2017

(C) The Author(s) 2017. This article is an open access publication

\begin{abstract}
Exposure to altitude results in multiple physiological consequences. These include, but are not limited to, a reduced maximal oxygen consumption, drop in arterial oxygen saturation, and increase in muscle metabolic perturbations at a fixed sub-maximal work rate. Exercise capacity during fixed work rate or incremental exercise and time-trial performance are also impaired at altitude relative to sea level. Recently, dietary nitrate $\left(\mathrm{NO}_{3}{ }^{-}\right)$supplementation has attracted considerable interest as a nutritional aid during altitude exposure. In this review, we summarise and critically evaluate the physiological and performance effects of dietary $\mathrm{NO}_{3}{ }^{-}$supplementation during exposure to simulated and terrestrial altitude. Previous investigations at simulated altitude indicate that $\mathrm{NO}_{3}{ }^{-}$supplementation may reduce the oxygen cost of exercise, elevate arterial and tissue oxygen saturation, improve muscle metabolic function, and enhance exercise capacity/performance. Conversely, current evidence suggests that $\mathrm{NO}_{3}{ }^{-}$ supplementation does not augment the training response at simulated altitude. Few studies have evaluated the effects of $\mathrm{NO}_{3}{ }^{-}$at terrestrial altitude. Current evidence indicates potential improvements in endothelial function at terrestrial altitude following $\mathrm{NO}_{3}{ }^{-}$supplementation. No effects of
\end{abstract}

Oliver Michael Shannon

O.Shannon@LeedsBeckett.ac.uk

1 Research Institute for Sport, Physical Activity, and Leisure, Leeds Beckett University, Leeds LS6 3QS, UK

2 Swedish Winter Sports Research Centre, Department of Health Sciences, Mid Sweden University, Östersund, Sweden

3 Defence Medical Services, Royal Centre for Defence Medicine, Birmingham B152TH, UK

4 Institute of Cellular Medicine, University of Newcastle, Newcastle upon Tyne NE45PL, UK
$\mathrm{NO}_{3}{ }^{-}$supplementation have been observed on oxygen consumption or arterial oxygen saturation at terrestrial altitude, although further research is warranted. Limitations of the present body of literature are discussed, and directions for future research are provided.

\section{Key Points}

The findings of this review demonstrate that dietary nitrate $\left(\mathrm{NO}_{3}{ }^{-}\right)$supplementation may reduce the oxygen cost of exercise, elevate arterial and tissue oxygenation, improve muscle metabolic function, and enhance exercise capacity/performance at simulated altitude.

Current preliminary evidence from training studies conducted at simulated altitude suggests that $\mathrm{NO}_{3}{ }^{-}$ supplementation has no effect on performancerelated adaptations, although further investigations are warranted.

Additional studies are required to confirm whether the beneficial effects of $\mathrm{NO}_{3}{ }^{-}$supplementation that have been demonstrated at simulated altitude also manifest at terrestrial altitude.

\section{Introduction}

Every year, millions of individuals ascend to altitude for recreational, occupational, and sporting purposes [1]. Reasons for ascending to altitude include, amongst others, tourism, hiking and mountaineering, skiing, military 
deployment, sports training camps, and athletic competition. With increasing altitude, there is a decrease in barometric pressure and a concomitant decline in the partial pressure of oxygen $\left(\mathrm{PO}_{2}\right)$, such that the high-altitude environment is hypoxic relative to sea level (normoxia). Exposure to this hypoxic environment decreases the amount of oxygen $\left(\mathrm{O}_{2}\right)$ reaching the lungs, blood, and ultimately tissue $[2,3]$. Consequently, maximal $\mathrm{O}_{2}$ consumption $\left(\dot{\mathrm{V}}_{2 \max }\right)$ decreases $[4,5]$. The absolute $\dot{\mathrm{V}} \mathrm{O}_{2}$ necessary to maintain a given sub-maximal work rate is typically the same at sea level and altitude up to $\sim 4300 \mathrm{~m}$, although it may be slightly reduced at higher altitudes (e.g., $5260 \mathrm{~m}$ ) consequent to alterations in substrate oxidation [6]. Nevertheless, the relative percentage of $\dot{\mathrm{V}}_{2 \max }$ utilized is higher at altitude relative to sea level [7]. As such, muscle metabolic perturbations are increased [8-11]. Furthermore, exercise time to exhaustion (TTE) and time-trial (TT) performance are impaired at altitude compared with sea level [7]. Prolonged altitude exposure results in acclimatization, comprising multiple renal, cardio-pulmonary, and hematological adaptations that act to increase the delivery of $\mathrm{O}_{2}$ to the tissue [12]. However, these adaptive changes can take days or weeks to fully manifest, and sea-level exercise performance/capacity is never fully attained, even with prolonged acclimatization [7].

Nitric oxide (NO) is a pleiotropic signaling molecule and a regulator of multiple physiological processes, many of which are altered by hypoxia, including mitochondrial function [13, 14], cerebral and muscle tissue blood flow [15-17], muscle metabolism [10, 11], and endothelial function $[18,19]$. NO plays a fundamental role in the response to hypoxia and has been implicated in hypoxiainduced vasodilation, a mechanism designed to ensure appropriate matching between $\mathrm{O}_{2}$ delivery and the metabolic demands of muscle and cerebral tissue when $\mathrm{O}_{2}$ availability is low [15, 20]. Elevated levels of NO [21], alongside hematological (e.g., erythropoiesis and increased hemoglobin mass) and ventilatory (e.g., increased hypoxic ventilatory response) changes [22], have been associated with successful adaptation and acclimatization to altitude in lowlanders and altitude residents. In particular, Tibetan highlanders who have adapted to the genetic selection pressures of living at high altitude, manifest greatly increased plasma and pulmonary NO bioavailability $[18,23,24]$. Such adaptations afford distinctive metabolic [25] and microcirculatory [18] benefits that translate into an extraordinary capacity to cope with the challenges of hypoxia relative to unacclimatized lowlanders. Conversely, prior to acclimatization, lowlanders exhibit suppressed NO bioavailability with altitude exposure, and both failure to acclimatize and high-altitude illness have been associated with insufficient NO generation in hypoxia [26-28].
Given the importance of NO during hypoxic exposure, it has been widely speculated that increasing NO bioavailability via dietary supplementation might confer beneficial effects in individuals ascending to altitude [29-32]. Endogenous NO production occurs via two distinct and uniquely different pathways that may be targeted to increase NO generation. First, NO can be produced via oxidation of the semi-essential amino acid L-arginine. This reaction is catalyzed by the NO synthase (NOS) enzymes and requires $\mathrm{O}_{2}$ as a co-substrate. In vitro evidence suggests that NO generated via the L-arginine NOS pathway is suppressed in hypoxia [33], although in vivo evidence is less clear [34-36]. Alternatively, NO can be generated via the reduction of nitrate $\left(\mathrm{NO}_{3}{ }^{-}\right)$and nitrite $\left(\mathrm{NO}_{2}{ }^{-}\right)$through the recently elucidated $\mathrm{NO}_{3}{ }^{-}-\mathrm{NO}_{2}{ }^{-}-\mathrm{NO}$ pathway [37]. Consumption of $\mathrm{NO}_{3}{ }^{-}$-rich foods such as leafy green vegetables and beetroot or $\mathrm{NO}_{3}{ }^{-}$-salts (e.g., sodium [Na]or potassium $\left[\mathrm{K}^{+}\right]-\mathrm{NO}_{3}{ }^{-}$) rapidly and substantially elevates plasma $\left[\mathrm{NO}_{3}{ }^{-}\right]$(square brackets denote concentration) [38]. Exogenous $\mathrm{NO}_{3}{ }^{-}$mixes with endogenously derived $\mathrm{NO}_{3}{ }^{-}$, which is an oxidation product of the $\mathrm{L}-$ arginine NOS pathway, in the blood and can be slowly reduced to $\mathrm{NO}_{2}{ }^{-}$by the enzyme xanthine oxidoreductase [39]. A more rapid pathway for $\mathrm{NO}_{3}{ }^{-}$reduction also exists, which is facilitated through recirculation of $\mathrm{NO}_{3}{ }^{-}$into the mouth via the salivary glands [40]. Here, oral bacteria reduce $\mathrm{NO}_{3}{ }^{-}$to $\mathrm{NO}_{2}{ }^{-}$via reductase enzymes [41]. A portion of the bacterially generated $\mathrm{NO}_{2}{ }^{-}$is transformed into NO in the stomach $[42,43]$. However, the majority enters systemic circulation and may be further reduced to NO via enzymatic and non-enzymatic catalysts [37, 44] including, amongst others, xanthine oxidoreductase [45, 46], deoxygenated hemoglobin [47] and myoglobin [48], and cytochrome c oxidase (COX) [49]. Importantly, these pathways for $\mathrm{NO}$ generation via $\mathrm{NO}_{2}{ }^{-}$reduction are all considerably enhanced in hypoxic conditions [37]. The $\mathrm{NO}_{3}{ }^{-}-\mathrm{NO}_{2}{ }^{-}-\mathrm{NO}$ pathway is therefore of particular importance in hypoxia and is viewed as an important "back-up" system for maintaining and/or enhancing NO bioavailability and signaling in this environment (Fig. 1). It should be noted that recent evidence suggests a possible direct role of $\mathrm{NO}_{2}{ }^{-}$on skeletal muscle and mitochondrial function and in hypoxia-induced vasodilation [50]. Thus, any effects of $\mathrm{NO}_{3}{ }^{-}$consumption might, at least in part, be related to $\mathrm{NO}_{2}{ }^{-}$-dependent signaling, rather than being solely attributable to NO [50].

Interestingly, recent evidence from studies conducted at sea level suggests that $\mathrm{NO}_{3}{ }^{-}$supplementation can reduce resting blood pressure (BP) [51-53], lower the $\mathrm{O}_{2}$ cost of exercise [54-56], and augment both exercise capacity and performance [55, 57-59]. Logically, greater effects of $\mathrm{NO}_{3}{ }^{-}$supplementation might be expected in hypoxia, given the particularly important role that NO plays in this 




Fig. 1 A schematic representation of the metabolic pathways for nitric oxide (NO) generation in the human body (adapted from Jones [32], with permission). The 'traditional' pathway for NO generation involves oxidation of the semi-essential amino acid L-arginine, in a reaction which requires the availability of $\mathrm{O}_{2}$ and is catalysed via the NO synthase (NOS) enzymes. This $\mathrm{O}_{2}$-dependent reaction is suppressed in hypoxia. Alternatively, NO can be generated via the nitrate $\left(\mathrm{NO}_{3}{ }^{-}\right)$-nitrite $\left(\mathrm{NO}_{2}{ }^{-}\right)-\mathrm{NO}$ pathway. Here, $\mathrm{NO}_{3}{ }^{-}$from

environment and that $\mathrm{NO}$ production via the L-arginine NOS pathway is suppressed yet $\mathrm{NO}_{2}^{-}$reduction is enhanced in hypoxia. Furthermore, a reduced $\mathrm{O}_{2}$ cost of exercise is likely to be especially meaningful for individuals exercising in a low- $\mathrm{O}_{2}$ environment.

Although several recent articles have been published reviewing the potential benefits of dietary $\mathrm{NO}_{3}{ }^{-}$supplementation at sea level $[31,32,59-61]$, there is presently no review of the literature focusing on its specific applications for individuals exercising at altitude, despite a considerable and broad body of evidence emerging in the area. The purpose of the present review is to address this need by summarizing and critically evaluating the findings of recent research exploring the effects of $\mathrm{NO}_{3}{ }^{-}$supplementation on cardiopulmonary and metabolic responses to exercise and exercise performance at altitude. The potential effects of $\mathrm{NO}_{3}{ }^{-}$supplementation on adaptations to altitude training are also explored. Throughout the review, key limitations of the present body of evidence will be discussed and directions for future research suggested. dietary sources or produced as an oxidation product of the L-arginine pathway is reduced into $\mathrm{NO}_{2}{ }^{-}$via oral bacteria (a rapid pathway) or via the enzyme xanthine oxidoreductase (XOR) (a slower pathway). $\mathrm{NO}_{2}{ }^{-}$can subsequently be reduced into $\mathrm{NO}$ via multiple catalysts, particularly under conditions of low $\mathrm{O}_{2}$ availability. This second pathway may serve to maintain or enhance NO signalling under conditions of hypoxia, such as that experienced at an altitude

\section{Study Selection and Characteristics}

Studies were identified for this review by searching online journals and the databases PubMed and SPORTDiscus. This review includes studies that assessed the effects of $\mathrm{NO}_{3}{ }^{-}$supplementation during both acute $(\sim 1-5 \mathrm{~h})$ and chronic (1-28 days) altitude exposure. We included studies conducted at terrestrial altitude, simulated altitude via normobaric hypoxia (i.e., the altitude $\mathrm{PO}_{2}$ is replicated by lowering the fraction of inspired $\mathrm{O}_{2}\left[\mathrm{~F}_{\mathrm{I}} \mathrm{O}_{2}\right]$ whilst maintaining sea-level barometric pressure), and hypobaric hypoxia (i.e., the altitude $\mathrm{PO}_{2}$ is replicated by lowering the barometric pressure whilst the $\mathrm{F}_{\mathrm{I}} \mathrm{O}_{2}$ is unchanged from sealevel values). Terrestrial altitudes ranged from 1300 to $5300 \mathrm{~m}$. Reported simulated altitudes were $\sim 2500-5000 \mathrm{~m}\left(\mathrm{~F}_{\mathrm{I}} \mathrm{O}_{2}\right.$ 11-15.4\%) in normobaric hypoxia and $3500 \mathrm{~m}$ in a hypobaric chamber. The dose of $\mathrm{NO}_{3}{ }^{-}$ ranged from $\sim 5$ to $15.2 \mathrm{mmol} \cdot \mathrm{day}^{-1}$. Supplementation duration ranged from an acute dose $1.5-3 \mathrm{~h}$ pre-trial, to chronic loading for up to 11 days. 


\section{Physiological Effects of Nitrate $\left(\mathrm{NO}_{3}{ }^{-}\right)$ Supplementation in Hypoxia}

\subsection{Oxygen $\left(\mathrm{O}_{2}\right)$ Consumption During Steady-State Constant Work-Rate Exercise}

Larsen et al. [54] first reported a reduction in steady-state $\dot{\mathrm{V}} \mathrm{O}_{2}$ consequent to $\mathrm{NO}_{3}{ }^{-}$supplementation with $\dot{\mathrm{V}}_{2} \sim 5 \%$ lower during cycle ergometry exercise in normoxia. This effect was unexpected, as the $\mathrm{V}_{2}$ requirement of a given workload is typically regarded as unchangeable, but has since been confirmed in multiple subsequent investigations in normoxia [38, 55-57, 62, 63].

Masschelein et al. [29] confirmed the $\mathrm{O}_{2}$-sparing effect of $\mathrm{NO}_{3}{ }^{-}$supplementation during exercise in normobaric hypoxia. $\dot{\mathrm{V}} \mathrm{O}_{2}$ was $\sim 4 \%$ lower during cycle ergometry exercise at $45 \%$ peak $\mathrm{O}_{2}$ uptake $\left(\dot{\mathrm{V}}_{2 \text { peak }}\right)$ in extreme normobaric hypoxia $\left(\mathrm{F}_{\mathrm{I}} \mathrm{O}_{2} 11 \%, \sim 5000 \mathrm{~m}\right)$. Subsequent studies have reported $\dot{\mathrm{V}}_{2}$ reductions of $4-10 \%$ (similar magnitudes to those reported in normoxia) during cycle ergometry $[29,30,36]$ and treadmill running exercise [64] across a range of simulated altitudes $\left(\mathrm{F}_{\mathrm{I}} \mathrm{O}_{2}\right.$ 11-15.4\%, $\sim 2500-5000 \mathrm{~m}$ ). Interestingly, one study reported lower steady-state $\dot{\mathrm{V}}_{2}$ in normobaric hypoxia $\left(\mathrm{F}_{\mathrm{I}} \mathrm{O}_{2} 13.1 \%\right.$, $\sim 3500 \mathrm{~m}$ ) but not normoxia [36] following $\mathrm{NO}_{3}{ }^{-}$supplementation. This suggests that $\mathrm{NO}_{3}{ }^{-}$supplementation might be especially effective at reducing the $\mathrm{O}_{2}$ cost of exercise in hypoxia, possibly due to greater conversion of $\mathrm{NO}_{2}{ }^{-}$into $\mathrm{NO}$ and/or more effective modulation of $\mathrm{O}_{2-}$ consuming cellular processes.

To the authors' knowledge, only one study has reported the effects of $\mathrm{NO}_{3}{ }^{-}$supplementation on $\mathrm{V}_{2}$ during acute exercise in hypobaric hypoxia [65]. In contrast to some evidence obtained in normobaric hypoxia, $\mathrm{NO}_{3}{ }^{-}$supplementation did not influence $\dot{\mathrm{V}}_{2}$ during cycle ergometry exercise in a hypobaric hypoxic chamber simulating $3500 \mathrm{~m}$ altitude. These inconsistent findings are puzzling but might be related to the high training status of the participants $\left(\dot{\mathrm{V}}_{2 \max }\right.$ at $1600 \mathrm{~m}$ altitude: $\sim 61 \mathrm{ml} \cdot \mathrm{kg}^{-1} \cdot \mathrm{min}^{-1}$; see Sect. 4 for details of how training status may modulate the effects of $\mathrm{NO}_{3}{ }^{-}$supplementation) rather than the exercise environment. Supporting this notion, three recent studies have reported no effect of $\mathrm{NO}_{3}{ }^{-}$supplementation on $\dot{\mathrm{V}}_{2}$ during sub-maximal exercise in normobaric hypoxia $\left(\mathrm{F}_{\mathrm{I}} \mathrm{O}_{2} 11-15.4 \%, \sim 2500-5000 \mathrm{~m}\right)$ in highlytrained individuals $\left(\dot{\mathrm{V}}_{2 \max }:>60 \mathrm{ml} \cdot \mathrm{kg}^{-1} \cdot \mathrm{min}^{-1}\right)$ [66-68]. Moreover, a recent investigation at sea level reported a significant inverse relationship between $\dot{\mathrm{V}}_{2 \text { peak }}$ and the reduction in $\mathrm{V}_{2}$ consequent to $\mathrm{NO}_{3}{ }^{-}$supplementation [58]. However, direct comparison of the effects of $\mathrm{NO}_{3}{ }^{-}$ ingestion on $\dot{\mathrm{V}}_{2}$ in normobaric and hypobaric hypoxia is warranted to exclude the influence of other potentially confounding methodological variables.

The reduction in $\mathrm{V}_{2}$ subsequent to $\mathrm{NO}_{3}{ }^{-}$supplementation is unlikely to be related to a shift towards anaerobic adenosine triphosphate (ATP) generation, as blood [lactate] [54], muscle $\mathrm{pH}$ [69], and glycolytic ATP turnover [62] are typically unchanged following $\mathrm{NO}_{3}{ }^{-}$ingestion. Instead, it has been suggested that the lower $\mathrm{VO}_{2}$ reported after $\mathrm{NO}_{3}{ }^{-}$ supplementation might be related to improvements in the efficiency of muscle force generation [62] and/or mitochondrial respiration [70].

In the study by Bailey et al. [62], $\mathrm{NO}_{3}{ }^{-}$supplementation attenuated intramuscular phosphocreatine ( $\mathrm{PCr}$ ), adenosine diphosphate $(\mathrm{ADP})$, and inorganic phosphate $\left(\mathrm{P}_{\mathrm{i}}\right)$ perturbations and lowered $\dot{\mathrm{V}}_{2}$ during leg-extension exercise in normoxia, suggesting a lower ATP cost of muscle force generation [62]. The ATP cost of muscle force production is primarily accounted for by cross-bridge cycling and calcium $\left(\mathrm{Ca}^{2+}\right)$ handling $[71,72]$. Given NO has been demonstrated to slow cross-bridge cycling kinetics [73, 74] and inhibit $\mathrm{Ca}^{2+}$-ATPase activity $[75,76]$, the lower ATP requirement of muscle force generation following $\mathrm{NO}_{3}{ }^{-}$ supplementation may be related to a NO-mediated reduction in the ATP cost of one or both of these processes [62]. Recently, Hernandez et al. [77] reported increased muscle force generation and elevated expression of the $\mathrm{Ca}^{2+}$ handling protein calsequestrin 1 and the dihydropyridine receptor in murine type II muscle fibers following $\mathrm{NO}_{3}{ }^{-}$ supplementation. It was proposed that similar effects in humans might allow muscle activation at a lower frequency for an equivalent force production, thus decreasing motor unit recruitment and lowering the ATP cost (and therefore improving the efficiency) of force production.

Larsen et al. [70] reported improvements in mitochondrial efficiency following $\mathrm{NO}_{3}{ }^{-}$supplementation. Supplementation with $\mathrm{NaNO}_{3}{ }^{-}$for 3 days increased the phosphate $/ \mathrm{O}_{2}(\mathrm{P} / \mathrm{O})$ ratio of mitochondria harvested from the vastus lateralis of healthy men, an effect that was significantly correlated with the reduced in vivo $\dot{\mathrm{VO}}_{2}$. The authors reported reduced expression of the ATP/ADP translocase protein (ANT) and a tendency towards reduced expression of uncoupling protein 3 (UCP3). Such effects may have reduced proton leak during oxidative phosphorylation and could account for the improved $\mathrm{P} / \mathrm{O}$ ratio and lower pulmonary $\dot{\mathrm{V}}_{2}$ [70]. It was proposed that these changes to protein expression may manifest as a consequence of $\mathrm{NO}$ competitively inhibiting $\mathrm{O}_{2}$ binding to $\mathrm{COX}$ [78], which may be detected by the mitochondria as hypoxia, activating signaling pathways that downregulate ANT [70]. Given greater inhibition of COX would be expected when $\mathrm{PO}_{2}$ is low, it is possible that this mechanism may be more active in hypoxia than in normoxia [61]. 
In contrast to the findings of Larsen et al. [70], Whitfield et al. [79] reported no effect of $\mathrm{NO}_{3}{ }^{-}$-rich beetroot juice on mitochondrial efficiency despite a reduced $\dot{\mathrm{V}}_{2}$. These disparate results may be related to the form of $\mathrm{NO}_{3}{ }^{-}$ administered (i.e., $\mathrm{NaNO}_{3}{ }^{-}$vs. beetroot juice), although direct comparison is required to eliminate other methodological discrepancies [80]. Interestingly, one recent study [81] reported greater reductions in $\mathrm{V}_{2}$ following beetroot juice versus $\mathrm{NaNO}_{3}{ }^{-}$supplementation in normoxia, possibly as a consequence of the beetroot juice polyphenols and antioxidants enhancing NO generation, further suggesting different effects of these two $\mathrm{NO}_{3}{ }^{-}$-containing supplements.

\section{$3.2 \mathrm{O}_{2}$ Uptake Kinetics}

Normoxic studies have reported faster phase II $\dot{\mathrm{VO}}_{2}$ kinetics during the transition from moderate to severe [82], but not unloaded to moderate $[55,82,83]$, intensity exercise following $\mathrm{NO}_{3}{ }^{-}$supplementation. The apparently greater effects of $\mathrm{NO}_{3}{ }^{-}$during the moderate to severe intensity transition might be related to type II muscle fiberspecific effects of $\mathrm{NO}_{3}{ }^{-}[61,77,84]$, given greater relative activation of these fibers during this transition [82]. In hypoxia, $\dot{\mathrm{V}} \mathrm{O}_{2}$ kinetics are typically slowed compared with normoxia [36, 85]. Interestingly, Kelly et al. [36] observed faster phase II $\dot{\mathrm{V}}_{2}$ kinetics during the step transition from unloaded to moderate-intensity but not moderate- to severe-intensity exercise in normobaric hypoxia [36]. Conversely, $\mathrm{NO}_{3}{ }^{-}$supplementation did not influence $\dot{\mathrm{V}} \mathrm{O}_{2}$ kinetics in normoxia in this study [36]. The precise reasons why $\mathrm{NO}_{3}{ }^{-}$had no effect on $\dot{\mathrm{V}}_{2}$ kinetics during the moderate to severe transition in hypoxia, or either transition in normoxia, are unclear. Nevertheless, the speeding of $\dot{\mathrm{V}}_{2}$ kinetics during the unloaded to moderate-intensity exercise transition might be beneficial by reducing the time required to reach a steady state and thus minimizing the incurred $\mathrm{O}_{2}$ deficit [86].

\subsection{Arterial $\mathrm{O}_{2}$ Saturation}

$\mathrm{NO}_{3}{ }^{-}$supplementation has been reported to result in a small (1-4\%) increase in arterial $\mathrm{O}_{2}$ saturation $\left(\mathrm{S}_{\mathrm{a}} \mathrm{O}_{2}\right)$, as assessed via pulse oximetry, in some $[29,30,64,68]$ but not all [36] studies during acute exposure to normobaric hypoxia. Carriker et al. [65] observed no effects of $\mathrm{NO}_{3}{ }^{-}$ on $\mathrm{S}_{\mathrm{a}} \mathrm{O}_{2}$ during acute exercise in a hypobaric hypoxic chamber $(\sim 3500 \mathrm{~m})$.

Only one study has examined the effects of $\mathrm{NO}_{3}{ }^{-}$supplementation on $\mathrm{S}_{\mathrm{a}} \mathrm{O}_{2}$ at terrestrial altitude [87]. Hennis et al. [87] observed no effect of $\mathrm{NO}_{3}{ }^{-}$on $\mathrm{S}_{\mathrm{a}} \mathrm{O}_{2}$ during an 11-day trek to Mount Everest Base Camp ( $\sim 5300 \mathrm{~m})$. The lack of effect in this study may be related to the chronic hypoxic exposure and gradual altitude ascent. Here, endogenous NO generation may be elevated with acclimatization [21], thus potentially diminishing the reliance on exogenous $\mathrm{NO}_{3}{ }^{-}$as a substrate for $\mathrm{NO}$ generation. $\mathrm{NO}_{3}{ }^{-}$might therefore be more effective during acute altitude exposure prior to acclimatization, where NO bioavailability is reduced. However, this awaits direct investigation.

Apnea (i.e., breath holding) investigations provide further insight into the effects of $\mathrm{NO}_{3}{ }^{-}$supplementation on $\mathrm{S}_{\mathrm{a}} \mathrm{O}_{2}$ when $\mathrm{O}_{2}$ availability is restricted. $\mathrm{NO}_{3}{ }^{-}$supplementation has been reported to elevate $\mathrm{S}_{\mathrm{a}} \mathrm{O}_{2}$ during static [88] and dynamic [89] apneas. Conversely, Schiffer et al. [90] observed lower $\mathrm{S}_{\mathrm{a}} \mathrm{O}_{2}$ values and decreased static apnea duration following $\mathrm{NO}_{3}{ }^{-}$supplementation. However, $\mathrm{NO}_{3}{ }^{-}$supplementation tended to elevate $\mathrm{S}_{\mathrm{a}} \mathrm{O}_{2}$ during a maximal dynamic apnea. These conflicting results might be related to methodological differences between studies, including the type of apnea (e.g., static vs. dynamic, underwater vs. 'dry'), $\mathrm{NO}_{3}{ }^{-}$supplementation strategy, and pre-apnea hyperventilation procedures. Nevertheless, the evidence that $\mathrm{NO}_{3}{ }^{-}$supplementation can elevate $\mathrm{S}_{\mathrm{a}} \mathrm{O}_{2}$ in certain apnea situations, particularly during dynamic apnea, provides support for the increase in $\mathrm{S}_{\mathrm{a}} \mathrm{O}_{2}$ observed during exercise in hypoxia $[29,30,64,68]$.

Mechanistically, the elevated $\mathrm{S}_{\mathrm{a}} \mathrm{O}_{2}$ reported during exercise in hypoxia following $\mathrm{NO}_{3}{ }^{-}$supplementation may be due to reduced muscle $\mathrm{O}_{2}$ extraction consequent to improvements in the efficiency of muscle contraction [62] and/or mitochondrial respiration [70]. Additionally, in one study, $\mathrm{NO}_{3}{ }^{-}$supplementation increased pulmonary ventilation $(\dot{\mathrm{V}} E)$ in conjunction with an elevated $\mathrm{S}_{\mathrm{a}} \mathrm{O}_{2}$ during exercise in hypoxia [68]. Given a higher $\dot{V} E$ has previously been associated with reduced arterial desaturation [91], it is possible that an increased $\dot{\mathrm{V}} E$ following $\mathrm{NO}_{3}{ }^{-}$supplementation might also play a role in elevating $\mathrm{S}_{\mathrm{a}} \mathrm{O}_{2}$. An elevated $\mathrm{S}_{\mathrm{a}} \mathrm{O}_{2}$ could have important implications for hypoxic exercise performance, as discussed in Sect. 4. Theoretically, an elevated $\mathrm{S}_{\mathrm{a}} \mathrm{O}_{2}$ could also help attenuate acute mountain sickness [92], although current studies have reported no significant effect of $\mathrm{NO}_{3}{ }^{-}$on acute mountain sickness [29, 87].

\subsection{Tissue Oxygenation}

Masschelein et al. [29] reported an increase in the nearinfrared spectroscopy (NIRS)-derived tissue oxygenation index (TOI) of the vastus lateralis during cycle ergometry exercise in normobaric hypoxia $\left(\mathrm{F}_{\mathrm{I}} \mathrm{O}_{2} 11 \%, \sim 5000 \mathrm{~m}\right)$ following $\mathrm{NO}_{3}{ }^{-}$supplementation. Kelly et al. [36] also reported a tendency towards elevated TOI during 
moderate-intensity exercise in normobaric hypoxia $\left(\mathrm{F}_{\mathrm{I}} \mathrm{O}_{2}\right.$ $13.1 \%, \sim 3500 \mathrm{~m}$ ). The TOI reflects the ratio between absolute values of oxygenated and total haemoglobin plus myoglobin, and therefore provides a measure of local oxygenation status. Masschelein et al. [29] interpreted the increased TOI as reflecting a greater $\mathrm{O}_{2}$ efficiency consequent to $\mathrm{NO}_{3}{ }^{-}$. Alternatively, the increased TOI could reflect a greater $\mathrm{O}_{2}$ delivery to the muscle due to elevated tissue blood flow [93]. As both hypoxia [94] and $\mathrm{NO}_{3}{ }^{-}$ [95] have been reported to increase tissue blood flow, this second explanation cannot be excluded. Given the possible influence of skin blood flow (which increases for thermoregulatory purposes during exercise) on the NIRS signal [96], caution is also advised when interpreting these data. Additional information on the strengths and limitations of NIRS is presented elsewhere [93, 97].

\subsection{Muscle Metabolism}

Exposure to hypoxia reduces both arterial and intracellular $\mathrm{PO}_{2}$ [3]. This has a deleterious effect on muscle metabolic function, reducing the capacity for oxidative ATP resynthesis $[8,14]$, increasing the degradation of limited metabolic substrates including muscle glycogen and $\mathrm{PCr}$ and elevating the accumulation of fatigue-associated metabolites such as $\mathrm{H}^{+}, \mathrm{P}_{\mathrm{i}}$, and ADP [9-11]. These factors potentially contribute towards the decreased exercise tolerance in hypoxia [98]. Intriguingly, Vanhatalo et al. $[11,99]$ provide evidence to suggest that $\mathrm{NO}_{3}{ }^{-}$supplementation might ameliorate the undesirable effects of hypoxia on muscle metabolic function.

$\mathrm{NO}_{3}{ }^{-}$supplementation attenuated the rate of change in muscle $[\mathrm{PCr}],\left[\mathrm{P}_{\mathrm{i}}\right]$, and $\mathrm{pH}$ as assessed via ${ }^{31}$ phosphorusmagnetic resonance spectroscopy $\left({ }^{31} \mathrm{P}-\mathrm{MRS}\right)$ during leg extension exercise in normobaric hypoxia $\left(\mathrm{F}_{\mathrm{I}} \mathrm{O}_{2} 14.5 \%\right.$, $\sim 2800 \mathrm{~m}$ ) [11]. Muscle PCr recovery, reflective of muscle oxidative capacity, was restored to normoxic values. In a follow-up study in more severe hypoxia $\left(\mathrm{F}_{\mathrm{I}} \mathrm{O}_{2} \quad 13 \%\right.$, $\sim 3500 \mathrm{~m}$ ), the faster $\mathrm{PCr}$ recovery kinetics with $\mathrm{NO}_{3}{ }^{-}$ supplementation were associated with an accelerated effective transverse relaxation time (T2*), as obtained via magnetic resonance imaging (MRI) [99]. The T2* signal is a result of both blood flow to the area under investigation and the oxygenation status of the blood and tissue. Consequently, an increase in blood volume and/or the proportion of oxygenated blood increases the T2* signal [100]. The authors speculated that the accelerated $\mathrm{T} 2 *$ recovery following $\mathrm{NO}_{3}{ }^{-}$supplementation may indicate a greater delivery of freshly oxygenated blood to the muscle, increasing the $\mathrm{O}_{2}$ driving pressure into the muscle cells, and resulting in faster oxidative ATP resynthesis and $\mathrm{PCr}$ regeneration [99]. $\mathrm{NO}_{3}{ }^{-}$supplementation also improved mitochondrial efficiency, as indicated by an increased muscle phosphorylation potential (indicative of the proton motive force) and lower Gibb's free energy $(\Delta G)$ [99]. Interestingly, resting [PCr] was reduced consequent to $\mathrm{NO}_{3}{ }^{-}$supplementation, with the magnitude of the decline inversely correlated with plasma $\left[\mathrm{NO}_{2}{ }^{-}\right]$. It was speculated that this might be related to reversible S-nitrosation of creatine kinase (CK), and could serve to enhance mitochondrial sensitivity to ADP stimulation. Thus, $\mathrm{NO}_{3}{ }^{-}$ supplementation may enhance both muscle energetics and $\mathrm{O}_{2}$ delivery during hypoxic exercise, which might partly underpin the improvements in exercise performance discussed in Sect. 4.

\subsection{Cardiovascular Response}

In normoxia, $\mathrm{NO}_{3}{ }^{-}$supplementation has been reported to reduce BP [51-53] and enhance vascular compliance [101] in humans and improve cardiac contractility in rodents [102]. Dietary $\mathrm{NO}_{3}{ }^{-}$might also provide a means of altering the complex and multifaceted cardiovascular response to hypoxia.

Some [11, 64], but not all [68, 103], previous studies have reported BP reductions during acute normobaric hypoxic exposure following $\mathrm{NO}_{3}{ }^{-}$supplementation. The reduced $\mathrm{BP}$ following $\mathrm{NO}_{3}{ }^{-}$supplementation has been attributed to increased $\mathrm{NO}_{2}{ }^{-}$and $\mathrm{NO}$ generation and subsequent vasodilation [52, 53]. Recently, Ingram et al. [104] reported pulmonary and arterial vasodilation after $\mathrm{NO}_{2}{ }^{-}$ infusion in normobaric hypoxia $\left(\mathrm{F}_{\mathrm{I}} \mathrm{O}_{2} 12 \%, \sim 4100 \mathrm{~m}\right)$ but not normoxia. The greater activity of $\mathrm{NO}_{2}{ }^{-}$reductases, including xanthine oxidoreductase, deoxygenated hemoglobin, and myoglobin, and COX in hypoxia [37] may partly explain this effect. Interestingly, Ingram et al. [104] observed pulmonary vasodilation in hypoxia after plasma $\left[\mathrm{NO}_{2}{ }^{-}\right]$had returned to baseline values. This suggests possible storage and metabolism of $\mathrm{NO}_{2}{ }^{-}$, and $\mathrm{NO}$ in the extravascular tissue could contribute to hypoxia-induced vasodilation [104]. It is possible, based on the findings of Ingram et al. [104], that the capacity to elicit vasodilation and $\mathrm{BP}$ effects with $\mathrm{NO}_{3}{ }^{-}$supplementation might also be more likely in hypoxia than in normoxia, although direct comparison is required.

In acute normobaric hypoxia $\left(\mathrm{F}_{\mathrm{I}} \mathrm{O}_{2} \sim 11.6 \%, \sim 4600 \mathrm{~m}\right)$, $\mathrm{NO}_{3}{ }^{-}$supplementation neither influenced the hemodynamic response nor augmented cardiac unloading in healthy men [103]. Similarly, $\mathrm{NO}_{3}{ }^{-}$had no effect on the hypoxia-induced hyperemic response to handgrip exercise in young adults (mean \pm standard deviation [SD] age $25 \pm 1$ years) exercising in normoxia and acute normobaric hypoxia $\left(\mathrm{F}_{\mathrm{I}} \mathrm{O}_{2}\right.$ titrated to achieve $\sim 80 \% \mathrm{~S}_{\mathrm{a}} \mathrm{O}_{2}$ ) [105]. Interestingly, despite similar increases in plasma $\left[\mathrm{NO}_{2}{ }^{-}\right], \mathrm{NO}_{3}{ }^{-}$supplementation significantly increased the vasodilation and blood flow response to hypoxic exercise in older participants 
(mean \pm SD age $64 \pm 2$ years). The magnitude of the effect was such that age-related differences in compensatory vasodilation were abolished with $\mathrm{NO}_{3}{ }^{-}$supplementation, suggesting therapeutic utility of $\mathrm{NO}_{3}{ }^{-}$in older populations exercising in hypoxia [105] or potentially those afflicted with clinical conditions involving tissue hypoxia [106].

Limited evidence is available regarding the effects of $\mathrm{NO}_{3}{ }^{-}$on cardiovascular parameters at terrestrial altitude. Bakker et al. [19] and Hennis et al. [87] reported no effects of $\mathrm{NO}_{3}{ }^{-}$supplementation on BP during prolonged treks at terrestrial altitude. However, in the study by Bakker et al. [19], acute $\mathrm{NO}_{3}{ }^{-}$ingestion offset the decline in endothelial function assessed via flow-mediated vasodilation (FMD) in healthy young participants (mean \pm SD age $25 \pm 5$ years) during an expedition in Nepal ( 28 days $>2500 \mathrm{~m}$, including a peak of $3700 \mathrm{~m}$ ). FMD has traditionally been viewed as reflecting NO-dependent vasodilation of the smooth muscle in response to acute hyperemia following circulatory occlusion [107, 108]. The hyperemia that manifests following occlusion is believed to increase G-protein expression of phosphokinase $\mathrm{A}$ and subsequently increase activity of endothelial NOS (eNOS) [108]. NO is then generated via eNOS catabolism of L-arginine, which ultimately results in smooth muscle relaxation and vasodilation [108]. Based on this conventional view, Bakker et al. [19] primarily attributed the beneficial effects of $\mathrm{NO}_{3}{ }^{-}$supplementation on FMD to elevated $\mathrm{NO}$ bioavailability via the $\mathrm{NO}_{3}{ }^{-}-\mathrm{NO}_{2}{ }^{-}-\mathrm{NO}$ pathway and subsequent effects on smooth muscle. However, there exists considerable debate about the NO-dependency of this technique, with some authors supporting [109-111] and others questioning [112-115] the role of NO in FMD assessment. Further exploration may therefore be warranted to understand the precise mechanisms through which $\mathrm{NO}_{3}{ }^{-}$supplementation influences FMD.

\section{Hypoxic Exercise Performance}

Several studies have examined the effects of $\mathrm{NO}_{3}{ }^{-}$ingestion on exercise capacity/performance in acute normobaric hypoxia (Table 1). The effects of $\mathrm{NO}_{3}{ }^{-}$supplementation on exercise capacity/performance in simulated altitude via hypobaric hypoxia and at terrestrial altitude have yet to be investigated. Vanhatalo et al. [11] were the first to study the effects of $\mathrm{NO}_{3}{ }^{-}$supplementation during exercise in normobaric hypoxia $\left(\mathrm{F}_{\mathrm{I}} \mathrm{O}_{2} 14.5 \%, \sim 2800 \mathrm{~m}\right)$ and observed a $21.4 \%$ increase in leg-extension TTE with $\mathrm{NO}_{3}{ }^{-}$supplementation. This improvement effectively restored exercise duration to normoxia values. Whilst exhaustive leg-extension exercise is not directly representative of athletic performance, these data suggest that $\mathrm{NO}_{3}{ }^{-}$supplementation might offer a means of ameliorating the ergolytic effects of hypoxia on exercise performance.
Masschelein et al. [29] confirmed the beneficial effects of $\mathrm{NO}_{3}{ }^{-}$supplementation in extreme normobaric hypoxia $\left(\mathrm{F}_{\mathrm{I}} \mathrm{O}_{2} 11 \%\right.$, $\left.5000 \mathrm{~m}\right)$. Cycle ergometry TTE was reduced by $36 \%$ in hypoxia versus normoxia. However, $\mathrm{NO}_{3}{ }^{-}$ supplementation attenuated $\sim 5 \%$ of this ergolytic effect. The magnitude of this effect is substantially lower than that reported by Vanhatalo et al. [11], although it is likely of practical relevance to an athlete and may be accounted for by methodological differences. Notably, in the study by Vanhatalo et al. [11], exercise was conducted in moderate hypoxia involving a small muscle group, whereas Masschelein et al. [29] had participants complete whole-body exercise in severe hypoxia. In the former, a beneficial effect of $\mathrm{NO}_{3}{ }^{-}$on muscle $\mathrm{O}_{2}$ efficiency may result in a direct and substantial improvement in performance, given muscles are over perfused and muscle $\dot{\mathrm{VO}}_{2}$ is predominantly limited by mitochondrial $\mathrm{O}_{2}$ consumption rather than delivery of $\mathrm{O}_{2}$ to the muscle [11]. In the latter, muscle $\mathrm{O}_{2}$ consumption is limited primarily by impaired $\mathrm{O}_{2}$ diffusion, consequent to the drop in arterial $\mathrm{PO}_{2}$, such that greater $\mathrm{O}_{2}$ efficiency may result in smaller performance improvements [29]. Additionally, constant-load TTE tests, as employed by Vanhatalo et al. [11], are typically more sensitive than incremental TTE tests for detecting improvements in exercise capacity [29, 116].

Muggeridge et al. [30] first assessed the effects of $\mathrm{NO}_{3}{ }^{-}$ supplementation on TT performance rather than TTE in normobaric hypoxia $\left(\mathrm{F}_{\mathrm{I}} \mathrm{O}_{2} 15 \%, \sim 2500 \mathrm{~m}\right)$. Performance in a pre-loaded (i.e., preceded by a steady-state period) 16.1-km cycle ergometry TT was significantly faster (2.2\%) following $\mathrm{NO}_{3}{ }^{-}$supplementation. Kelly et al. [36] reported similar beneficial effects of $\mathrm{NO}_{3}{ }^{-}$on severe-intensity cycle ergometry TTE in physically active males $\left(\right.$ mean $\pm \mathrm{SD} \quad \dot{\mathrm{V}}{ }_{2 \text { peak }}: 58.3 \pm 6.3 \mathrm{ml} \cdot \mathrm{kg}^{-1} \cdot \mathrm{min}^{-1}$ ) exercising in normobaric hypoxia $\left(\mathrm{F}_{\mathrm{I}} \mathrm{O}_{2} 13.1 \%\right.$, $\left.3500 \mathrm{~m}\right)$. Interestingly, $\mathrm{NO}_{3}{ }^{-}$supplementation did not influence exercise tolerance in normoxia in this study [36], supporting the notion that the ergogenic effects of $\mathrm{NO}_{3}{ }^{-}$might be particularly pronounced in conditions of low $\mathrm{O}_{2}$ availability. Most recently, Shannon et al. [64] reported a significant improvement in pre-loaded 1500-m running TT performance in normobaric hypoxia $\left(\mathrm{F}_{\mathrm{I}} \mathrm{O}_{2} \sim 15 \%\right.$, $\sim 2500 \mathrm{~m}$ ) following $\mathrm{NO}_{3}{ }^{-}$supplementation in participants across a range of different fitness levels $\left(\dot{\mathrm{VO}}_{2 \max }\right.$ range: $47.1-76.8 \mathrm{ml} \cdot \mathrm{kg}^{-1} \cdot \mathrm{min}^{-1}$ ). All 12 participants in that study were faster with $\mathrm{NO}_{3}{ }^{-}$supplementation than with placebo, with an average improvement in $1500 \mathrm{~m} \mathrm{TT}$ performance of $3.2 \%$.

However, not all studies have observed a positive effect of $\mathrm{NO}_{3}{ }^{-}$supplementation on hypoxic exercise performance. MacLeod et al. [66] reported no effects of $\mathrm{NO}_{3}{ }^{-}$ supplementation on $10-\mathrm{km}$ cycle ergometry TT 


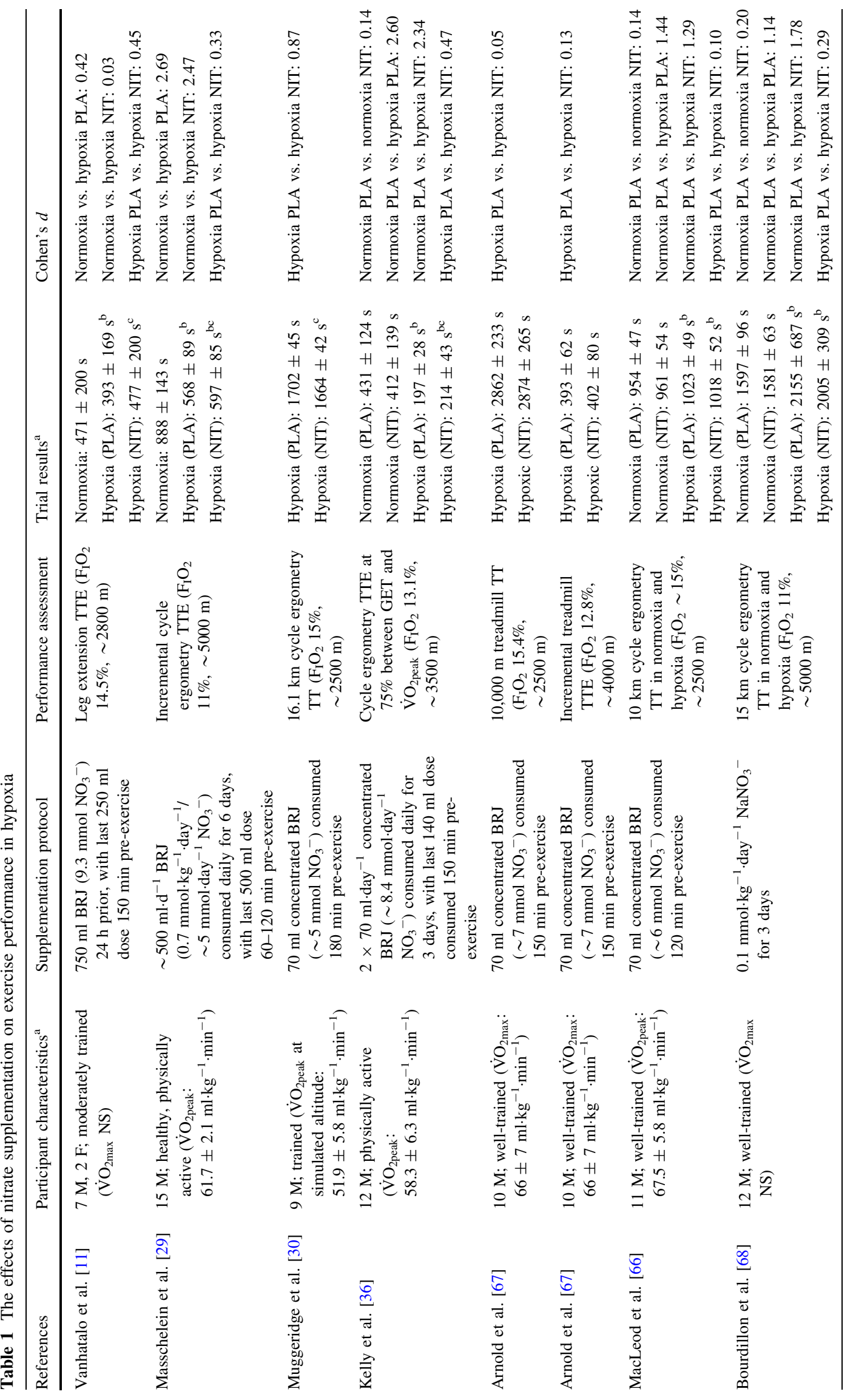


performance in well-trained athletes (mean $\pm \mathrm{SD} \dot{\mathrm{V}} \mathrm{O}_{2 \text { peak }}$ $67.5 \pm 5.8 \mathrm{ml} \cdot \mathrm{kg}^{-1} \cdot \mathrm{min}^{-1}$ ) exercising in either normobaric hypoxia $\left(\mathrm{F}_{\mathrm{I}} \mathrm{O}_{2} \sim 15 \%, \sim 2500 \mathrm{~m}\right)$ or normoxia. Likewise, Bourdillon et al. [68] observed no significant difference in $15-\mathrm{km}$ cycle ergometry TT performance in extreme normobaric hypoxia $\left(\mathrm{F}_{\mathrm{I}} \mathrm{O}_{2} 11 \%, \sim 5000 \mathrm{~m}\right)$ or normoxia following $\mathrm{NO}_{3}{ }^{-}$supplementation. However, there was a non-significant tendency towards improved performance $(\sim 151 \mathrm{~s}$ faster $)$ in hypoxia with $\mathrm{NO}_{3}{ }^{-}$ ingestion. Similarly, Arnold et al. [67] reported no effect of $\mathrm{NO}_{3}{ }^{-}$ingestion on $10-\mathrm{km}$ TT running performance in moderate normobaric hypoxia $\left(\mathrm{F}_{\mathrm{I}} \mathrm{O}_{2} 15.4 \%, \sim 2500 \mathrm{~m}\right)$ or incremental running performance in extreme normobaric hypoxia $\left(\mathrm{F}_{\mathrm{I}} \mathrm{O}_{2} 12.8 \%, \sim 4000 \mathrm{~m}\right)$ in highly trained runners (mean $\pm \mathrm{SD} \dot{\mathrm{V}} \mathrm{O}_{2 \max } 66 \pm 7 \mathrm{ml} \cdot \mathrm{kg}^{-1} \cdot \mathrm{min}^{-1}$ ).

These conflicting results might be explained by methodological differences between investigations. At present, some evidence exists to suggest that the training status of participants, exercise protocol, supplementation protocol, and exercise environment (i.e., the degree and duration of hypoxic exposure) can all moderate the effects of $\mathrm{NO}_{3}{ }^{-}$supplementation [31]. However, it should be noted that none of these variables alone can entirely explain the apparent ergogenic effect of $\mathrm{NO}_{3}{ }^{-}$supplementation (or lack thereof), and it is the interaction between these and other factors that appears to be important.

In several normoxic studies, high aerobic fitness has been suggested as a possible reason for minimal effects of $\mathrm{NO}_{3}{ }^{-}$on exercise performance [117-122]. Notably, Porcelli et al. [58] suggested that untrained and moderately trained $\left(\dot{\mathrm{V}}_{2 \max }<60 \mathrm{ml} \cdot \mathrm{kg}^{-1} \cdot \mathrm{min}^{-1}\right)$ individuals are more likely to benefit from $\mathrm{NO}_{3}{ }^{-}$supplementation than endurance-trained athletes $\left(\dot{\mathrm{V}}_{2 \max }>60 \mathrm{ml} \cdot \mathrm{kg}^{-1} \cdot \mathrm{min}^{-1}\right)$. However, given the cross-sectional nature of this study and relatively modest sample size (fitness-stratified sub-groups of six to eight participants), these data should be interpreted with caution. Moreover, a recent meta-analysis found no influence of aerobic fitness on the response to $\mathrm{NO}_{3}{ }^{-}$supplementation [59], bringing into question this relationship. Nevertheless, as evident in Shannon et al. [64], who observed beneficial effects of $\mathrm{NO}_{3}{ }^{-}$in participants across a spectrum of fitness levels during exercise in moderate normobaric hypoxia, a high training status does not entirely preclude an ergogenic effect of $\mathrm{NO}_{3}{ }^{-}$supplementation. Given that $\mathrm{NO}_{3}{ }^{-}$supplementation appears to be more effective in hypoxia than in normoxia [123], it is possible that individuals who may not benefit from $\mathrm{NO}_{3}{ }^{-}$ supplementation in normoxia (or at low/moderate altitudes) might derive an ergogenic effect in extreme hypoxia where the $\mathrm{NO}_{3}{ }^{-}-\mathrm{NO}_{2}{ }^{-}-\mathrm{NO}$ pathway is enhanced yet NOS activity is suppressed. 
$\mathrm{NO}_{3}{ }^{-}$supplementation appears to be most effective during short-duration high-intensity exercise, although data are presently limited regarding the effects of $\mathrm{NO}_{3}{ }^{-}$ on this type of exercise at altitude. During short-duration high-intensity activity, the cellular environment is likely to be particularly hypoxic and acidic, potentiating $\mathrm{NO}_{2}{ }^{-}$ reduction into NO [49, 124]. Moreover, type II muscle is likely to be highly activated, and compelling evidence from murine models suggests that $\mathrm{NO}_{3}{ }^{-}$supplementation might solely increase perfusion to $[84,95]$ and contractile function/force generation of [77] type II muscle. Whilst a precise 'cut-off' duration or exercise intensity for the effects of $\mathrm{NO}_{3}{ }^{-}$supplementation to be meaningful has yet to be established and will likely differ depending on other experimental factors, it appears that $\mathrm{NO}_{3}{ }^{-}$supplementation is usually beneficial for exercise tests lasting $<30 \min [55,57,58,62,63,125,126]$, but usually not longer [117, 118, 120, 127], at least in normoxia. Exercise at altitude, particularly mountaineering and hiking, can include sustained periods of relatively low-intensity activity. The effects of $\mathrm{NO}_{3}{ }^{-}$supplementation on key physiological and functional (e.g., walking distance in a given time period) parameters during this type of exercise warrant further study, especially as only a small proportion of people ascending to altitude are highly trained athletes conducting high-intensity exercise. Interestingly, Kuennen et al. [128] reported a lower $\mathrm{O}_{2}$ cost of exercise during a simulated desert march in the heat $\left(41{ }^{\circ} \mathrm{C}\right)$ consequent to $\mathrm{NO}_{3}{ }^{-}$supplementation. Given the similarity of this exercise mode to altitude hiking (i.e., relatively low-intensity walking whilst carrying a backpack), it is possible that $\mathrm{NO}_{3}{ }^{-}$supplementation might also reduce $\mathrm{O}_{2}$ consumption during altitude hiking, although this has yet to be investigated. The effect of $\mathrm{NO}_{3}{ }^{-}$supplementation at lower altitudes $(<2500 \mathrm{~m}>$ sea level $)$ also remains unexplored yet is of interest given physiological functioning may be influenced by altitudes as low as 300-800 m [4].

Finally, normoxic studies suggest the supplementation strategy might influence the ergogenic effects of $\mathrm{NO}_{3}{ }^{-}$. First, there is evidence to indicate a possible dose response to $\mathrm{NO}_{3}{ }^{-}$supplementation $[38,129,130]$. Likewise, some effects of $\mathrm{NO}_{3}{ }^{-}$, particularly those requiring changes in protein expression [70,77], may require several days to occur, suggesting chronic loading may be more effective than acute supplementation [59, 63]. Interestingly, Flueck et al. [81] reported greater reductions in $\dot{\mathrm{V}}_{2}$ with beetroot juice than with $\mathrm{NaNO}_{3}{ }^{-}$supplementation, which could be related to greater $\mathrm{NO}_{2}{ }^{-}$reduction into $\mathrm{NO}$ with beetroot juice consequent to the polyphenols and/or antioxidants. The potential influence of these moderators awaits investigation in hypoxia.

\subsection{Simulated Versus Terrestrial Altitude}

To date, few studies have explored the efficacy of $\mathrm{NO}_{3}{ }^{-}$ supplementation during exposure to terrestrial altitude $[19,87,131]$, presumably because of the high financial costs and logistical difficulties associated with such investigations. Instead, researchers have typically administered inspired hypoxic gas during exercise or conducted exercise in normobaric or (to a lesser degree) hypobaric hypoxic chambers. There is ongoing debate about potential differences in the physiological response to normobaric hypoxia and terrestrial altitude [132], including potential disparities in NO metabolism [133]. Further investigations into the effects of $\mathrm{NO}_{3}{ }^{-}$at terrestrial altitude and/or contrasting the effects of $\mathrm{NO}_{3}{ }^{-}$supplementation between terrestrial and simulated altitude is warranted. It seems likely that $\mathrm{NO}_{3}{ }^{-}$supplementation could enhance exercise performance at terrestrial altitude, given exercise performance is predominantly limited by the low $\mathrm{PO}_{2}$ in both normobaric and hypobaric hypoxia [29]. Furthermore, $\mathrm{NO}_{3}{ }^{-}$ supplementation has been reported to improve endothelial function at terrestrial altitude, suggesting the potential to alter peripheral vascular function in this environment [19]. Given the large degree of "noise" associated with fieldbased testing, future studies may require large sample sizes to ensure sufficient power to detect any meaningful physiological changes with $\mathrm{NO}_{3}{ }^{-}$supplementation.

\section{Training in Hypoxia}

There remains a degree of ambiguity over the performance effects of $\mathrm{NO}_{3}{ }^{-}$supplementation during exercise in hypoxia, as discussed in Sect. 4. Nevertheless, it is possible that $\mathrm{NO}_{3}{ }^{-}$supplementation could help augment the physiological and performance adaptations to training in hypoxia, if the maintainable work rate during training sessions was enhanced or prolonged. Moreover, NO has been implicated in the adaptation to hypoxia [21] and appears to play a role in skeletal muscle hypertrophy and fiber-type transitions [134] and endothelial adaptations [135], but not mitochondrial biogenesis [136, 137], following exercise training. Increasing NO bioavailability via $\mathrm{NO}_{3}{ }^{-}$supplementation might therefore enhance some of the adaptations to hypoxic training. Conversely, it is also possible that $\mathrm{NO}_{3}{ }^{-}$might suppress hypoxic training adaptations by limiting the drop in arterial and muscle $\mathrm{O}_{2}$ saturation, factors that could serve as "signals" for adaptation to hypoxic training [138].

Puype et al. [138] found no effect of $\mathrm{NO}_{3}{ }^{-}$supplementation on the physiological and performance adaptations to 6 weeks of high-intensity endurance training 
$\left(5 \times 30 \mathrm{~min} \cdot \mathrm{week}^{-1}\right.$ cycle ergometry at $4-6 \mathrm{mmol} \cdot \mathrm{l}^{-1}$ blood [lactate]) in normobaric hypoxia $\left(\mathrm{F}_{\mathrm{I}} \mathrm{O}_{2} 12.5 \%\right.$, $\sim 4000 \mathrm{~m}$ ). Improvements in $\dot{\mathrm{V}} \mathrm{O}_{2 \max }$, power output at the onset of blood lactate accumulation (OBLA; $4 \mathrm{mmol} \cdot \mathrm{l}^{-1}$ blood [lactate]) and average power output during a 30-min TT in normoxia were similar in $\mathrm{NO}_{3}{ }^{-}$and placebo conditions. Likewise, the pre- to post-hypoxic training change was similar between groups for muscle adenosine monophosphate-activated kinase (AMPK) protein content and phosphorylation, hypoxia-inducible factor (HIF)- $1 \alpha$ messenger RNA (mRNA) content, and glycogen breakdown during the TT. More recently, De Smet et al. [139] explored the effects of $\mathrm{NO}_{3}{ }^{-}$on adaptations to sprint interval training (SIT) in normobaric hypoxia $\left(\mathrm{F}_{\mathrm{i}} \mathrm{O}_{2} 15 \%\right.$, $\sim 2500 \mathrm{~m}$ ) versus separate unsupplemented normoxic and hypoxic training groups. Participants completed $3 \times 4-6$ maximal $30 \mathrm{~s}$ cycle ergometry sprints per week over a 5 -week period. The proportion of type IIa fibers was significantly increased in the hypoxic $\mathrm{NO}_{3}{ }^{-}$group, whereas the proportion of type IIx fibers was significantly decreased. By contrast, a significant decrease in the proportion of type IIx fibers in the unsupplemented groups did not lead to significant increases in other fiber-type groups. These findings were coupled with a tendency towards greater improvements in normoxic 30 -s sprint performance in the hypoxic $\mathrm{NO}_{3}{ }^{-}$training group relative to the hypoxic unsupplemented training group. Conversely, performance in a 30-min TT completed in normoxia increased by similar amounts in all groups. Taken together, the results of Puype et al. [138] and De Smet et al. [139] suggest that $\mathrm{NO}_{3}{ }^{-}$ supplementation consumed during 5-6 weeks of endurance or sprint training in hypoxia has minimal effects on physiological adaptations or on exercise performance in normoxia.

Two studies have also recently explored the effects of $\mathrm{NO}_{3}{ }^{-}$supplementation on the adaptations to SIT in normoxia [140, 141]. Muggeridge et al. [140] reported greater improvements in maximal work rate during incremental exercise and indices of repeated high-intensity performance in participants who ingested $\mathrm{NO}_{3}{ }^{-}$versus placebo prior to SIT sessions $(3 \times 4-6$ maximal $15 \mathrm{~s}$ cycle ergometry sprints per week, for 3 weeks). Thompson et al. [141] also demonstrated greater improvements in peak work rate during incremental exercise in individuals who performed SIT (3-4 $\times 4-5$ maximal 30 s cycle ergometry sprints per week for 4 weeks) with $\mathrm{NO}_{3}{ }^{-}$compared with both training individuals given a placebo and $\mathrm{NO}_{3}{ }^{-}$-supplemented individuals who did not train. Interestingly, and supporting the findings of De Smet et al. [139], Thompson et al. [141] showed a decrease in the proportion of type IIx muscle fibers in the vastus lateralis in participants completing SIT with $\mathrm{NO}_{3}{ }^{-}$but not in the other conditions.
Based on the findings of these studies, it is possible that $\mathrm{NO}_{3}{ }^{-}$may elicit similar muscle fiber-type changes when consumed parallel to training in normoxia and hypoxia but may be more effective at enhancing performance adaptations to normoxic than hypoxic training. However, this requires direct investigation given the multifarious methodological differences between studies. In particular, Puype et al. [138] and De Smet et al. [139] in hypoxia recruited moderately trained participants $\left(\dot{\mathrm{V}}_{2 \max }: \sim 51-\right.$ $\left.60 \mathrm{ml} \cdot \mathrm{kg}^{-1} \cdot \mathrm{min}^{-1}\right)$, whereas Muggeridge et al. [140] and Thompson et al. [141] in normoxia recruited individuals with lower aerobic fitness $\left(\dot{\mathrm{V}}_{2 \max }\right.$ : $\sim 42-50 \mathrm{ml} \cdot \mathrm{kg}^{-1-}$ $\min ^{-1}$ ), who may exhibit a greater response to training with $\mathrm{NO}_{3}{ }^{-}$.

The approach adopted in the above studies is similar to most training-intervention studies, whereby a standardized exercise session is utilized throughout the intervention, either with or without an overload component [142-145]. This strategy is seldom adopted by 'real-world' athletes, who instead perform a wide variety of training sessions [146-148]. Interestingly, anecdotal reports suggest that some elite endurance athletes at high-altitude training camps selectively use $\mathrm{NO}_{3}{ }^{-}$supplements (e.g., beetroot juice) in an attempt to maximize performance in some, but not all, training sessions. This approach, first highlighted by Professor Andrew Jones of Exeter University, UK [31, 32], may allow athletes to benefit from conducting key training sessions at higher exercise intensities. Conversely, low-intensity high-mileage sessions are performed unsupplemented, thus maximizing the hypoxic stimulus for adaptation [31, 32]. Periodizing $\mathrm{NO}_{3}{ }^{-}$supplementation in hypoxia has yet to be evaluated scientifically but may offer valuable psychological advantages to athletes regardless of the potential physiological merits.

\section{Summary and Conclusions}

$\mathrm{NO}_{3}{ }^{-}$supplementation is emerging as a promising nutritional aid, with potentially beneficial applications for the wide variety of individuals ascending to altitude each year. In this review, $\mathrm{NO}_{3}{ }^{-}$supplementation has been demonstrated to reduce pulmonary $\dot{\mathrm{V}}_{2}$ and, in some cases, elevate $\mathrm{S}_{\mathrm{a}} \mathrm{O}_{2}$ in normobaric hypoxia-effects that may be attributable to improvements in the efficiency of muscle contraction and/or mitochondrial respiration, and are of functional relevance for individuals exercising in a low- $\mathrm{O}_{2}$ environment. Current evidence also suggests that $\mathrm{NO}_{3}{ }^{-}$ supplementation can improve muscle energetics during exercise in normobaric hypoxia via effects on tissue $\mathrm{O}_{2}$ delivery and consumption and might alter cardiovascular responses to normobaric and hypobaric hypoxia. In 
contrast, whilst $\mathrm{NO}_{3}{ }^{-}$supplementation might influence some of the physiological responses to hypoxic training, current evidence suggests that this does not translate into improved exercise performance in normoxia. Given that the majority of published investigations have explored the effects of $\mathrm{NO}_{3}{ }^{-}$supplementation in simulated altitude, which is often regarded as an incomplete surrogate of "true" altitude, future studies at terrestrial altitude are necessary. Researchers are encouraged to further probe the myriad potentially beneficial effects of $\mathrm{NO}_{3}{ }^{-}$supplementation as a potential aid to "beet-ing" the mountain.

\section{Compliance with Ethical Standards}

Funding No sources of funding were used to assist in the preparation of this article.

Conflicts of interest Oliver Shannon, Kerry McGawley, Linn Nybäck, Lauren Duckworth, Matthew Barlow, David Woods, Mario Siervo, and John O'Hara have no conflicts of interest relevant to the content of this review.

Open Access This article is distributed under the terms of the Creative Commons Attribution 4.0 International License (http:// creativecommons.org/licenses/by/4.0/), which permits unrestricted use, distribution, and reproduction in any medium, provided you give appropriate credit to the original author(s) and the source, provide a link to the Creative Commons license, and indicate if changes were made.

\section{References}

1. Dumont L, Lysakowski C, Tramèr MR, et al. Controversies in altitude medicine. Travel Med Infect Dis. 2005;3:183-8.

2. Richardson RS, Duteil S, Wary C, et al. Human skeletal muscle intracellular oxygenation: the impact of ambient oxygen availability. J Physiol. 2006;571:415-24.

3. Calbet JA, Lundby C. Air to muscle $\mathrm{O}_{2}$ delivery during exercise at altitude. High Alt Med Biol. 2009;10:123-34.

4. Wehrlin JP, Hallén J. Linear decrease in $\mathrm{VO}_{2 \max }$ and performance with increasing altitude in endurance athletes. Eur J Appl Physiol. 2006;96:404-12.

5. MacInnis MJ, Nugent SF, MacLeod KE, et al. Methods to estimate $\mathrm{VO}_{2 \max }$ upon acute hypoxia exposure. Med Sci Sports Exerc. 2015;47:1869-76.

6. Lundby C, Calbet JA, Sander M, et al. Exercise economy does not change after acclimatization to moderate to very high altitude. Scand J Med Sci Sports. 2007;17:281-91.

7. Fulco CS, Rock PB, Cymerman A. Maximal and submaximal exercise performance at altitude. Aviat Space Environ Med. 1998;69:793-801.

8. Magalhães J, Ascensão A, Soares JMC, et al. Acute and severe hypobaric hypoxia increases oxidative stress and impairs mitochondrial function in mouse skeletal muscle. J Appl Physiol. 2005;99:1247-53.

9. Linnarsson D, Karlsson J, Fagraeus L, et al. Muscle metabolites and oxygen deficit with exercise in hypoxia and hyperoxia. J Appl Physiol. 1974;36:399-402.

10. Hogan MC, Richardson RS, Haseler LJ. Human muscle performance and $\mathrm{PCr}$ hydrolysis with varied inspired oxygen fractions: a 31P-MRS study. J Appl Physiol. 1999;86:1367-73.
11. Vanhatalo A, Fulford J, Bailey SJ, et al. Dietary nitrate reduces muscle metabolic perturbation and improves exercise tolerance in hypoxia. J Physiol. 2011;589:5517-28.

12. Mason NP. The physiology of high altitude: an introduction to the cardio-respiratory changes occurring on ascent to altitude. Curr Anaesth Crit Care. 2000;11:34-41.

13. Clerc P, Rigoulet M, Leverve X, et al. Nitric oxide increases oxidative phosphorylation efficiency. J Bioenerg Biomembr. 2007;39:158-66.

14. Solaini G, Baracca A, Lenaz G, et al. Hypoxia and mitochondrial oxidative metabolism. Biochim Biophys Acta. 2010;1797:1171-7.

15. Van Mil AHM, Spilt A, Van Buchem MA, et al. Nitric oxide mediates hypoxia-induced cerebral vasodilation in humans. J Appl Physiol. 2002;92:962-6.

16. Hackett PH, Roach RC. High-altitude illness. N Engl J Med. 2001;345:107-14.

17. Joyner MJ, Casey DP. Muscle blood flow, hypoxia, and hypoperfusion. J Appl Physiol. 2014;116:852-7.

18. Erzurum SC, Ghosh S, Janocha AJ, et al. Higher blood flow and circulating NO products offset high-altitude hypoxia among Tibetans. Proc Natl Acad Sci. 2007;104:17593-8.

19. Bakker E, Engan H, Patrician A, et al. Acute dietary nitrate supplementation improves arterial endothelial function at high altitude: a double-blinded randomized controlled cross over study. Nitric Oxide. 2015;50:58-64.

20. Diesen DL, Hess DT, Stamler JS. Hypoxic vasodilation by red blood cells. Circ Res. 2008;103:545-53.

21. Levett DZ, Fernandez BO, Riley HL, et al. The role of nitrogen oxides in human adaptation to hypoxia. Sci Rep. 2011;1:109. doi:10.1038/srep00109.

22. Bärtsch P, Saltin B. General introduction to altitude adaptation and mountain sickness. Scand J Med Sci Sports. 2008;18:1-10.

23. Beall CM, Laskowski D, Strohl KP, et al. Pulmonary nitric oxide in mountain dwellers. Nature. 2001;414:411-2.

24. Hoit BD. Nitric oxide and cardiopulmonary hemodynamics in Tibetan highlanders. J Appl Physiol. 2005;99:1796-801.

25. Marconi C, Marzorati M, Sciuto D, et al. Economy of locomotion in high-altitude Tibetan migrants exposed to normoxia. J Physiol. 2005;569:667-75.

26. Droma Y, Hanaoka M, Ota M, et al. Positive association of the endothelial nitric oxide synthase gene polymorphisms with highaltitude pulmonary edema. Circulation. 2002;106:826-30.

27. Bailey DM, Dehnert C, Luks AM, et al. High-altitude pulmonary hypertension is associated with a free radical-mediated reduction in pulmonary nitric oxide bioavailability. J Physiol. 2010;588:4837-47.

28. Beall CM, Laskowski D, Erzurum SC. Nitric oxide in adaptation to altitude. Free Radic Biol Med. 2012;52:1123-34.

29. Masschelein E, Van Thienen R, Wang X, et al. Dietary nitrate improves muscle but not cerebral oxygenation status during exercise in hypoxia. J Appl Physiol. 2012;113:736-45.

30. Muggeridge DJ, Howe CCF, Spendiff O, et al. A single dose of beetroot juice enhances cycling performance in simulated altitude. Med Sci Sports Exerc. 2014;46:143-50.

31. Jones AM. Influence of dietary nitrate on the physiological determinants of exercise performance: a critical review. Appl Physiol Nutr Metab. 2014;39:1019-28.

32. Jones AM. Dietary nitrate supplementation and exercise performance. Sports Med. 2014;44:35-45.

33. Fish JE, Matouk CC, Yeboah E, et al. Hypoxia-inducible expression of a natural cis-antisense transcript inhibits endothelial nitric-oxide synthase. J Biol Chem. 2007;282:15652-66.

34. Shaul PW, Wells LB, Horning KM. Acute and prolonged hypoxia attenuate endothelial nitric oxide production in rat 
pulmonary arteries by different mechanisms. J Cardiovasc Pharmacol. 1993;22:819-27.

35. Leuenberger UA, Johnson D, Loomis J, et al. Venous but not skeletal muscle interstitial nitric oxide is increased during hypobaric hypoxia. Eur J Appl Physiol. 2008;102:457-61.

36. Kelly J, Vanhatalo A, Bailey SJ, et al. Dietary nitrate supplementation: effects on plasma nitrite and pulmonary $\mathrm{O}_{2}$ uptake dynamics during exercise in hypoxia and normoxia. Am J Physiol. 2014;307:920-30.

37. Lundberg JO, Weitzberg E, Gladwin MT. The nitrate-nitritenitric oxide pathway in physiology and therapeutics. Nat Rev Drug Discov. 2008;7:156-67.

38. Wylie LJ, Kelly J, Bailey SJ, et al. Beetroot juice and exercise: pharmacodynamic and dose-response relationships. J Appl Physiol. 2013;115:325-36.

39. Jansson EA, Huang L, Malkey R, et al. A mammalian functional nitrate reductase that regulates nitrite and nitric oxide homeostasis. Nat Chem Biol. 2008;4:411-7.

40. Qin L, Liu X, Sun Q, et al. Sialin (SLC17A5) functions as a nitrate transporter in the plasma membrane. Proc Natl Acad Sci. 2012;109:13434-9.

41. Hyde ER, Andrade F, Vaksman Z, et al. Metagenomic analysis of nitrate-reducing bacteria in the oral cavity: implications for nitric oxide homeostasis. PLoS One. 2014;9(3):e88645. doi:10. 1371/journal.pone.0088645.

42. Benjamin N, O'Driscoll F, Dougall H, et al. Stomach NO synthesis. Nature. 1994;368:502.

43. Lundberg JO, Weitzberg E, Lundberg JM, et al. Intragastric nitric oxide production in humans: measurements in expelled air. Gut. 1994;35:1543-6.

44. Hunault CC, van Velzen AG, Sips AJAM, et al. Bioavailability of sodium nitrite from an aqueous solution in healthy adults. Toxicol Lett. 2009;190:48-53.

45. Godber BL, Doel JJ, Sapkota GP, et al. Reduction of nitrite to nitric oxide catalyzed by xanthine oxidoreductase. J Biol Chem. 2000;275:7757-63.

46. Cantu-Medellin N, Kelley EE. Xanthine oxidoreductase-catalyzed reduction of nitrite to nitric oxide: insights regarding where, when and how. Nitric Oxide. 2013;35:19-26.

47. Cosby K, Partovi KS, Crawford JH, et al. Nitrite reduction to nitric oxide by deoxyhemoglobin vasodilates the human circulation. Nat Med. 2003;9:1498-505.

48. Huang Z, Shiva S, Kim-Shapiro DB, et al. Enzymatic function of hemoglobin as a nitrite reductase that produces NO under allosteric control. J Clin Investig. 2005;115:2099-107.

49. Castello PR, David PS, McClure T, et al. Mitochondrial cytochrome oxidase produces nitric oxide under hypoxic conditions: implications for oxygen sensing and hypoxic signalling in eukaryotes. Cell Metab. 2006;3:277-87.

50. Affourtit C, Bailey SJ, Jones AM, et al. On the mechanism by which dietary nitrate improves human skeletal muscle function. Front Physiol. 2015;6:211. doi:10.3389/fphys.2015.00211.

51. Larsen FJ, Ekblom B, Sahlin K, et al. Effects of dietary nitrate on blood pressure in healthy volunteers. $\mathrm{N}$ Engl $\mathrm{J}$ Med. 2006;335:2792-3.

52. Webb AJ, Patel N, Loukogeorgakis S, et al. Acute blood pressure lowering, vasoprotective and anti-platelet properties of dietary nitrate via bioconversion to nitrite. Hypertension. 2008;51:784-90.

53. Siervo M, Lara J, Ogbonmwan I, et al. Inorganic nitrate and beetroot juice supplementation reduces blood pressure in adults: a systematic review and meta-analysis. $J$ Nutr. 2013;143:818-26.

54. Larsen FJ, Weitzberg E, Lundberg JO, et al. Effects of dietary nitrate on oxygen cost during exercise. Acta Physiol. 2007;191:59-66.
55. Bailey SJ, Winyard P, Vanhatalo A, et al. Dietary nitrate supplementation reduces the $\mathrm{O}_{2}$ cost of low-intensity exercise and enhances tolerance to high-intensity exercise in humans. J Appl Physiol. 2009;107:1144-55.

56. Pawlak-Chaouch M, Boissière J, Gamelin FX, et al. Effect of dietary nitrate supplementation on metabolic rate during rest and exercise in human: a systematic review and a meta-analysis. Nitric Oxide. 2016;53:65-76.

57. Cermak NM, Gibala MJ, van Loon LJ. Nitrate supplementation's improvement of $10-\mathrm{km}$ time-trial performance in trained cyclists. Int J Sport Nutr Exerc Metab. 2012;22:64-71.

58. Porcelli S, Ramaglia M, Bellistri G, et al. Aerobic fitness affects the exercise performance responses to nitrate supplementation. Med Sci Sports Exerc. 2015;47:1643-51.

59. McMahon NF, Leveritt MD, Pavey TG. The effect of dietary nitrate supplementation on endurance exercise performance in healthy adults: a systematic review and meta-analysis. Sports Med. 2017;47(4):735-56. doi:10.1007/s40279-016-0617-7.

60. Clements WT, Lee SR, Bloomer RJ. Nitrate ingestion: a review of the health and physical performance effects. Nutrients. 2014;6:5224-64.

61. Jones AM, Ferguson SK, Bailey SJ, et al. Fiber-type specific effects of dietary nitrate. Exerc Sport Sci Rev. 2016;44:53-60.

62. Bailey SJ, Fulford J, Vanhatalo A, et al. Dietary nitrate supplementation enhances muscle contractile efficiency during knee-extensor exercise in humans. J Appl Physiol. 2010;109:135-48.

63. Vanhatalo A, Bailey SJ, Blackwell JR, et al. Acute and chronic effects of dietary nitrate supplementation on blood pressure and the physiological responses to moderate-intensity and incremental exercise. Am J Physiol. 2010;299:1121-31.

64. Shannon OM, Duckworth L, Barlow MJ, et al. Dietary nitrate supplementation enhances high-intensity running performance in moderate normobaric hypoxia, independent of aerobic fitness. Nitric Oxide. 2016;30:59-63.

65. Carriker CR, Mermier CM, McLain TA, et al. Effect of acute dietary nitrate consumption on oxygen consumption during submaximal exercise in hypobaric hypoxia. Int $\mathbf{J}$ Sport Nutr Exerc Metab. 2015;26:315-22.

66. MacLeod KE, Nugent SF, Barr SI, et al. Acute beetroot juice supplementation does not improve cycling performance in normoxia or moderate hypoxia. Int J Sport Nutr Exerc Metab. 2015;25:359-66.

67. Arnold JT, Oliver SJ, Lewis-Jones TM, et al. Beetroot juice does not enhance altitude running performance in well-trained athletes. Appl Physiol Nutr Metab. 2015;40:590-5.

68. Bourdillon N, Fan JL, Uva B, et al. Effect of oral nitrate supplementation on pulmonary hemodynamics during exercise and time trial performance in normoxia and hypoxia: a randomized controlled trial. Front Physiol. 2015;6:288. doi:10.3389/fphys.2015.00288.

69. Fulford J, Winyard PG, Vanhatalo A, et al. Influence of dietary nitrate supplementation on human skeletal muscle metabolism and force production during maximum voluntary contractions. Eur J Physiol. 2013;465:517-28.

70. Larsen FJ, Schiffer TA, Borniquel S, et al. Dietary inorganic nitrate improves mitochondrial efficiency in humans. Cell Metab. 2011;13:149-59.

71. Bergstrom M, Hultman E. Energy cost and fatigue during intermittent electrical stimulation of human skeletal muscle. J Appl Physiol. 1988;65:1500-5.

72. Barclay CJ, Woledge RC, Curtin NA. Energy turnover for $\mathrm{Ca}^{2+}$ cycling in skeletal muscle. J Muscle Res Cell Motil. 2007;28:259-74.

73. Galler S, Hilber K, Göbesberger A. Effects of nitric oxide on force-generating proteins of skeletal muscle. Eur J Physiol. 1997;434:242-5. 
74. Heunks LM, Cody MJ, Geiger PC, et al. Nitric oxide impairs $\mathrm{Ca}^{2+}$ activation and slows cross-bridge cycling kinetics in skeletal muscle. J Appl Physiol. 2001;91:2233-9.

75. Ishii T, Sunami O, Saitoh N, et al. Inhibition of skeletal muscle sarcoplasmic reticulum $\mathrm{Ca}^{2+}$-ATPase by nitric oxide. FEBS Lett. 1998;440:218-22.

76. Viner RI, Williams TD, Schöneich C. Nitric oxide-dependent modification of the sarcoplasmic reticulum Ca-ATPase: localization of cysteine target sites. Free Radic Biol Med. 2000;29:489-96.

77. Hernandez A, Schiffer TA, Ivarsson N, et al. Dietary nitrate increases tetanic $\left[\mathrm{Ca}^{2+}\right] \mathrm{i}$ and contractile force in mouse fasttwitch muscle. J Physiol. 2012;590:3575-83.

78. Brown GC, Cooper CE. Nanomolar concentrations of nitric oxide reversibly inhibit synaptosomal respiration by competing with oxygen at cytochrome oxidase. FEBS Lett. 1994;356:295-8.

79. Whitfield J, Ludzki A, Heigenhauser GJF, et al. Beetroot juice supplementation reduces whole body oxygen consumption but does not improve indices of mitochondrial efficiency in human skeletal muscle. J Physiol. 2016;594:421-35.

80. Kemp GJ. Beetroot juice supplementation reduces the oxygen cost of exercise without improving mitochondrial efficiency: but how? J Physiol. 2016;594:253.

81. Flueck JL, Bogdanova A, Mettler S, et al. Is beetroot juice more effective than sodium nitrate? The effects of equimolar nitrate dosages of nitrate-rich beetroot juice and sodium nitrate on oxygen consumption during exercise. Appl Physiol Nutr Metab. 2016;41:421-9.

82. Breese BC, McNarry MA, Marwood S, et al. Beetroot juice supplementation speeds $\mathrm{O}_{2}$ uptake kinetics and improves exercise tolerance during severe-intensity exercise initiated from an elevated metabolic rate. Am J Physiol. 2013;305:1441-50.

83. Lansley KE, Winyard PG, Fulford J, et al. Dietary nitrate supplementation reduces the $\mathrm{O}_{2}$ cost of walking and running: a placebo-controlled study. J Appl Physiol. 2011;110:591-600.

84. Ferguson SK, Holdsworth CT, Wright JL, et al. Microvascular oxygen pressures in muscles comprised of different fiber types: impact of dietary nitrate supplementation. Nitric Oxide. 2015;48:38-43.

85. Hughson RL, Kowalchuk JM. Kinetics of oxygen uptake for submaximal exercise in hyperoxia, normoxia, and hypoxia. Can J Appl Physiol. 1995;20:198-210.

86. Burnley M, Jones AM. Oxygen uptake kinetics as a determinant of sports performance. Eur J Sport Sci. 2007;7:63-79.

87. Hennis PJ, Mitchell K, Gilbert-Kawai E, et al. Effects of dietary nitrate supplementation on symptoms of acute mountain sickness and basic physiological responses in a group of male adolescents during ascent to Mount Everest Base Camp. Nitric Oxide. 2016;60:24-31.

88. Engan HK, Jones AM, Ehrenberg F, et al. Acute dietary nitrate supplementation improves dry static apnea performance. Respir Physiol Neurobiol. 2012;182:53-9.

89. Patrician A, Schagatay E. Dietary nitrate enhances arterial oxygen saturation after dynamic apnea. Scand J Med Sci Sports. 2017;27(6):622-6. doi:10.1111/sms.12684.

90. Schiffer TA, Larsen FJ, Lundberg JO, et al. Effects of dietary inorganic nitrate on static and dynamic breath-holding in humans. Respir Physiol Neurobiol. 2013;185:339-48.

91. Benoit H, Busso T, Castells J, et al. Influence of hypoxic ventilatory response on arterial $\mathrm{O}_{2}$ saturation during maximal exercise in acute hypoxia. Eur J Appl Physiol. 1995;72:101-5.

92. Baumgartner RW, Bärtsch P, Maggiorini M, et al. Enhanced cerebral blood flow in acute mountain sickness. Aviat Space Environ Med. 1994;65:726-9.
93. Ferrari M, Mottola L, Quaresima V. Principles, techniques, and limitations of near infrared spectroscopy. Can J Appl Physiol. 2004;29:463-87.

94. Calbet JL, Boushel R, Rådegran G, et al. Determinants of maximal oxygen uptake in severe acute hypoxia. Am J Physiol. 2003;284:291-303.

95. Ferguson SK, Hirai DM, Copp SW, et al. Impact of dietary nitrate supplementation via beetroot juice on exercising muscle vascular control in rats. J Physiol. 2013;591:547-57.

96. Tew GA, Ruddock AD, Saxton JM. Skin blood flow differentially affects near-infrared spectroscopy-derived measures of muscle oxygen saturation and blood volume at rest and during dynamic leg exercise. Eur J Appl Physiol. 2010;110:1083-9.

97. Neary JP. Application of near infrared spectroscopy to exercise sports science. Can J Appl Physiol. 2004;29:488-503.

98. Allen DG, Lamb GD, Westerblad H. Skeletal muscle fatigue: cellular mechanisms. Physiol Rev. 2008;88:287-332.

99. Vanhatalo A, Jones AM, Blackwell JR, et al. Dietary nitrate accelerates post-exercise muscle metabolic recovery and $\mathrm{O}_{2}$ delivery in hypoxia. J Appl Physiol. 2014;117:1460-70.

100. Jacobi B, Bongartz G, Partovi S, et al. Skeletal muscle BOLD MRI: from underlying physiological concepts to its usefulness in clinical conditions. J Magn Reson Imaging. 2012;35:1253-65.

101. Bahra M, Kapil V, Pearl V, et al. Inorganic nitrate ingestion improves vascular compliance but does not alter flow-mediated dilatation in healthy volunteers. Nitric Oxide. 2012;26:197-202.

102. Pironti G, Ivarsson N, Yang J, et al. Dietary nitrate improves cardiac contractility via enhanced cellular $\mathrm{Ca}^{2+}$ signaling. Basic Res Cardiol. 2016;111:34.

103. Lefferts WK, Hughes WE, White CN, et al. Effect of acute nitrate supplementation on neurovascular coupling and cognitive performance in hypoxia. Appl Physiol Nutr Metab. 2016;41:133-41.

104. Ingram TE, Pinder AG, Bailey DM, et al. Low-dose sodium nitrite vasodilates hypoxic human pulmonary vasculature by a means that is not dependent on a simultaneous elevation in plasma nitrite. Am J Physiol. 2010;298:331-9.

105. Casey DP, Treichler DP, Ganger CT, et al. Acute dietary nitrate supplementation enhances compensatory vasodilation during hypoxic exercise in older adults. J Appl Physiol. 2015;118:178-86.

106. Kenjale AA, Ham KL, Stabler T, et al. Dietary nitrate supplementation enhances exercise performance in peripheral arterial disease. J Appl Physiol. 2011;110:1582-91.

107. Harris RA, Nishiyama SK, Wray DW, et al. Ultrasound assessment of flow-mediated dilation. Hypertension. 2010;55:1075-85.

108. Thijssen DHJ, Black MA, Pyke KE, et al. Assessment of flowmediated dilation in humans: a methodological and physiological guideline. Am J Physiol. 2011;300:2-12.

109. Green DJ, Jones H, Thijssen D, et al. Flow-mediated dilation and cardiovascular event prediction: does nitric oxide matter? Hypertension. 2011;57:363-9.

110. Green D. Point: Flow-mediated dilation does reflect nitric oxidemediated endothelial function. J Appl Physiol. 2005;99:1233-4.

111. Green DJ, Dawson EA, Groenewoud HMM, et al. Is flow-mediated dilation nitric oxide mediated? A meta-analysis. Hypertension. 2014;63:376-82.

112. Tschakovsky ME, Pyke KE. Counterpoint: Flow-mediated dilation does not reflect nitric oxide-mediated endothelial function. J Appl Physiol. 2005;99:1235-7.

113. Pyke K, Green DJ, Weisbrod C, et al. Nitric oxide is not obligatory for radial artery flow-mediated dilation following release of 5 or 10 min distal occlusion. Am J Physiol. 2010;298:119-26.

114. Parker BA, Tschakovsky ME, Augeri AL, et al. Heterogenous vasodilator pathways underlie flow-mediated dilation in men and women. Am J Physiol. 2011;301:1118-26. 
115. Wray DW, Witman MAH, Ives SJ, et al. Does brachial artery flow-mediated vasodilation provide a bioassay for NO? Hypertension. 2013;62:345-51.

116. Whipp BJ, Ward SA. Quantifying intervention-related improvements in exercise tolerance. Eur Respir J. 2009;33:1254-60.

117. Wilkerson DP, Hayward GM, Bailey SJ, et al. Influence of acute dietary nitrate supplementation on 50 mile time trial performance in well-trained cyclists. Eur J Appl Physiol. 2012;112:4127-34.

118. Cermak NM, Res P, Stinkens R, et al. No improvement in endurance performance after a single dose of beetroot juice. Int $\mathrm{J}$ Sport Nutr Exerc Metab. 2012;22:470-8.

119. Peacock U, Tjønna AE, James P, et al. Dietary nitrate does not enhance running performance in elite cross-country skiers. Med Sci Sports Exerc. 2012;44:2213-9.

120. Bescós R, Ferrer-Roca V, Galilea PA, et al. Sodium nitrate supplementation does not enhance performance of endurance athletes. Med Sci Sports Exerc. 2012;44:2400-9.

121. Christensen PM, Nyberg M, Bangsbo J. Influence of nitrate supplementation on $\mathrm{VO}_{2}$ kinetics and endurance of elite cyclists. Scand J Med Sci Sports. 2013;23:e21-31.

122. Lowings S, Shannon OM, Deighton K, et al. Effect of dietary nitrate supplementation on swimming performance in trained swimmers. Int J Sport Nutr Exerc Metab. 2017:1-24. doi:10. 1123/ijsnem.2016-0251.

123. Kelly J, Fulford J, Vanhatalo A, et al. Effects of short-term dietary nitrate supplementation on blood pressure, $\mathrm{O}_{2}$ uptake kinetics, and muscle and cognitive function in older adults. Am J Physiol. 2013;304:73-83.

124. Modin A, Björne H, Herulf M, et al. Nitrite-derived nitric oxide: a possible mediator of "acidic-metabolic" vasodilation. Acta Physiol Scand. 2001;171:9-16.

125. Lansley KE, Winyard PG, Bailey SJ, et al. Acute dietary nitrate supplementation improves cycling time trial performance. Med Sci Sports Exerc. 2011;43:1125-31.

126. Bond H, Morton L, Braakhuis AJ. Dietary nitrate supplementation improves rowing performance in well-trained rowers. Int J Sport Nutr Exerc Metab. 2012;22:251-6.

127. Lane SC, Hawley JA, Desbrow B, et al. Single and combined effects of beetroot juice and caffeine supplementation on cycling time trial performance. Appl Physiol Nutr Metab. 2014;39:1050-7.

128. Kuennen M, Jansen L, Gillum T, et al. Dietary nitrate reduces the $\mathrm{O}_{2}$ cost of desert marching but elevates the rise in core temperature. Eur J Appl Physiol. 2015;115:2557-69.

129. Wylie LJ, Ortiz de Zevallos J, Isidore T, et al. Dose-dependent effects of dietary nitrate on the oxygen cost of moderate-intensity exercise: acute vs. chronic supplementation. Nitric Oxide. 2016;57:30-9.

130. Hoon MW, Jones AM, Johnson NA, et al. The effect of variable doses of inorganic nitrate-rich beetroot juice on simulated 2,000$\mathrm{m}$ rowing performance in trained athletes. Int J Sports Physiol Perform. 2014;9:615-20.

131. Martin DS, Gilbert-Kawai ET, Meale PM, et al. Design and conduct of "Xtreme Alps": a double-blind, randomised controlled study of the effects of dietary nitrate supplementation on acclimatisation to high altitude. Contemp Clin Trials. 2013;36:450-9.
132. Coppel J, Hennis P, Gilbert-Kawai E, et al. The physiological effects of hypobaric hypoxia versus normobaric hypoxia: a systematic review of crossover trials. Extreme Physiol Med. 2015;4:2. doi:10.1186/s13728-014-0021-6.

133. Faiss R, Pialoux V, Sartori C, et al. Ventilation, oxidative stress, and nitric oxide in hypobaric versus normobaric hypoxia. Med Sci Sports Exerc. 2013;45:253-60.

134. Smith LW, Smith JD, Criswell DS. Involvement of nitric oxide synthase in skeletal muscle adaptation to chronic overload. J Appl Physiol. 2002;92:2005-11.

135. Kingwell BA, Sherrard B, Jennings GL, et al. Four weeks of cycle training increases basal production of nitric oxide from the forearm. Am J Physiol. 1997;272:1070-7.

136. Wadley GD, McConell GK. Effect of nitric oxide synthase inhibition on mitochondrial biogenesis in rat skeletal muscle. J Appl Physiol. 2007;102:314-20.

137. Wadley GD, Choate J, McConell GK. NOS isoform-specific regulation of basal but not exercise-induced mitochondrial biogenesis in mouse skeletal muscle. J Physiol. 2007;585:253-62.

138. Puype J, Ramaekers M, Van Thienen R, et al. No effect of dietary nitrate supplementation on endurance training in hypoxia. Scand J Med Sci Sports. 2014;25:234-41.

139. De Smet S, Van Thienen R, Deldicque L, et al. Nitrate intake promotes shift in muscle fiber type composition during sprint interval training in hypoxia. Front Physiol. 2016;7:233. doi:10. 3389/fphys.2016.00233.

140. Muggeridge DJ, Sculthorpe N, James PE, et al. The effects of dietary nitrate supplementation on the adaptations to sprint interval training in previously untrained males. J Sci Med Sport. 2017;20:92-7.

141. Thompson C, Wylie LJ, Blackwell JR, et al. Influence of dietary nitrate supplementation on physiological and muscle metabolic adaptations to sprint interval training. J Appl Physiol. 2016;122(3):642-52. doi:10.1152/japplphysiol.00909.2016.

142. Gaesser GA, Wilson LA. Effects of continuous and interval training on the parameters of the power-endurance time relationship for high-intensity exercise. Int $\mathrm{J}$ Sports Med. 1988;9:417-21.

143. Laursen PB, Shing CM, Peake JM, et al. Interval training program optimization in highly trained endurance cyclists. Med Sci Sports Exerc. 2002;34:1801-7.

144. Burgomaster KA, Howarth KR, Phillips SM, et al. Similar metabolic adaptations during exercise after low volume sprint interval and traditional endurance training in humans. J Physiol. 2008;586:151-60.

145. Seiler S, Jøranson K, Olesen BV, et al. Adaptations to aerobic interval training: interactive effects of exercise intensity and total work duration. Scand J Med Sci Sports. 2013;23:74-83.

146. Esteve-Lanao J, San Juan AF, Earnest CP, et al. How do endurance runners actually train? Relationship with competition performance. Med Sci Sports Exerc. 2005;37:496-504.

147. Seiler $\mathrm{S}$. What is best practice for training intensity and duration distribution in endurance athletes? Int J Sports Physiol Perform. 2010;5:276-91.

148. Tønnessen E, Sylta $\varnothing$, Haugen TA, et al. The road to gold: training and peaking characteristics in the year prior to a gold medal endurance performance. PLoS One. 2014;9(7):e101796. doi:10.1371/journal.pone.0101796. 